PNL-10171

UC-510

Report on Data Requirements and Hardware Selection for In-Situ Ball Viscometer

\author{
C. L. Shepard
}

December 1994

Prepared for the U.S. Department of Energy under Contract DE-ACO6-76RLO 1830

Pacific Northwest Laboratory Richland, Washington 99352

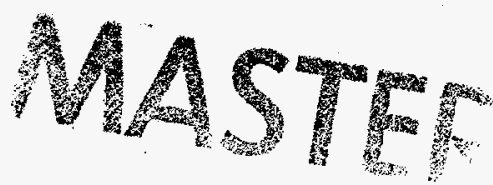





\section{DISCLAIMER}

This report was prepared as an account of work sponsored by an agency of the United States Government. Neither the United States Government nor any agency thereof, nor any of their employees, make any warranty, express or implied, or assumes any legal liability or responsibility for the accuracy, completeness, or usefulness of any information, apparatus, product, or process disclosed, or represents that its use would not infringe privately owned rights. Reference herein to any specific commercial product, process, or service by trade name, trademark, manufacturer, or otherwise does not necessarily constitute or imply its endorsement, recommendation, or favoring by the United States Government or any agency thereof. The views and opinions of authors expressed herein do not necessarily state or reflect those of the United States Government or any agency thereof. 


\section{DISCLAIMER}

Portions of this document may be illegible in electronic image products. Images are produced from the best available original document. 


\section{Contents}

Introduction $\ldots \ldots \ldots \ldots \ldots \ldots \ldots \ldots \ldots \ldots \ldots \ldots \ldots \ldots \ldots \ldots \ldots$

Data Requirements for Groups Involved with Tank $101-S Y \ldots \ldots \ldots \ldots \ldots \ldots$

Expected Instrument Performance $\ldots \ldots \ldots \ldots \ldots \ldots \ldots \ldots \ldots \ldots \ldots \ldots \ldots$

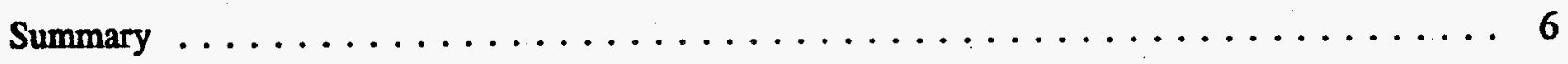




\title{
Report on Data Requirements and Hardware Selection for In-situ Ball Viscometer
}

\author{
Introduction
}

The in-situ ball rheometer is designed to provide data concerning the rheological properties of the waste contained in tank 101-SY. It is imperative that the data collected and the results obtained are useful to the community presently concerned with the mitigation of the waste contained within this tank. To ensure that this objective is met, discussions were held with representatives of different groups in order to determine their data needs. This report is a synopsis of these discussions. Four separate groups were identified as potential users of the data. Persons contacted included Don Trent (Pacific Northwest Laboratory (PNL)), who is involved with Tempest modelling of the tank; Randy Marlow and John Strehlow (Westinghouse Hanford Company (WHC)), involved with structural analysis of the tank; Kemal Pasamehmetoglu and Cetin Unal (Las Alamos National Laboratory (LANL)), who are concerned with the safety analysis of activities performed within the tank; and Judith Bamberger, Paul Scott, and Gita Golcar (PNL) who are involved with the eventual retrieval of waste from the tank. Very specific questions were asked of these groups, including:

1. From where in the tank are data needed?

2. When should data be collected?

3. In what manner are the data useful?

4. What is the required accuracy of the data?

Responses from each group are given below.

\section{Data Requirements for Groups Involved with Tank 101-SY}

Modelers of the behavior of the waste in tank 101-SY have the most global data requirements. Rheological data (density, yield stress, and apparent viscosity at low shear rates-less than $10 / \mathrm{sec}$ ) are needed in order to more accurately predict the behavior of the waste in this and other tanks through use of the TEMPEST code. The occurrence of tank rollover events is controlled in part by these parameters. Gas retention in the waste depends on the yield stress and the low shear rate viscosity. The tank region of interest is the nonconvective layer. They feel that the convective layer is presently well characterized and additional measurements will only tell them what is already known: Since rollovers may involve all or part of the nonconvective layer and modeling of the tank requires information on the entire tank, modelers would like to know the rheological properties everywhere in the nonconvective layer. In addition, they would like to know it at all times between gas release events. In addressing their needs, it is apparent that sampling should be performed over a suitable volume of the tank so that some realistic average value for the tank rheology can be obtained or some 
distribution of the rheological properties can be identified. In addition, sampling frequency should be high enough so that changes in rheological properties over time are observable. In the past, tank rollovers occurred at about six-month intervals, so sampling on at least a one-month interval probably would have been appropriate if rollovers were the sole concern. Essentially, data are required on the time scale for changes within the tank. With the mixer pump now in place and operational, this time scale may now be less than one month. However, a firm number will have to wait until more experience is obtained with the pump. Accuracy requirements are not very stringent, but firm and defendable numbers for accuracy requirements have not been forthcoming from this group. When pressed, it appears that $20 \%$ to $40 \%$ errors in the yield stress and zero shear rate viscosity values are certainly acceptable. Knowledge of the accuracy is important, so that allowances can be made in predicted results. Inaccuracies in rheological parameters affect results more or less linearly, so that a small error in yield strength will not result in a large error in predicted gas retention, for instance. The prospect of just the availability of any reasonably reliable data is cause for excitement within this community, and such data would represent a radical improvement over the present situation. Don Trent is not particularly concerned with accuracy at present and has pointed out that many questions concerning the ultimate accuracy of derived rheological properties cannot be addressed at this time. Only after some model development has been accomplished and simulant testing has been performed will we have a reasonable idea of how well the ball rheometer may perform, and the final answer may have to wait until actual tank data are obtained and analyzed. In the end, we will be limited in how well we can model the waste fluid, regardless of how well we measure velocity and drag force. This limit will depend somewhat on the rheological character of the waste itself. Because we cannot determine in advance the accuracy at which we derive rheological properties and we can answer such questions only after the ball rheometer has been built and deployed (at which time it's too late to address desired accuracy), it becomes rather pointless to worry excessively about accuracy. The accuracy will be whatever it is and we will simply live with it. All we can do is perform the force and velocity measurements as precisely as possible, recognize the limited range of usefulness of the instrument, and use it within that range. He remains confident that the derived rheological parameters will be of sufficient accuracy to be of great use to modelers and other data users. Considering the estimated error of around $1000 \%$ for present rheological values, his confidence is probably justified.

Safety assessment of tank activities also requires knowledge of rheological properties (density, yield strength, and apparent viscosity at strain rates less than about $10 / \mathrm{s}$ ). Safety assessment relies in part on the TEMPEST code for predictions, and so the rheological parameter range of interest is about the same as that of the modelers, as is the measurement frequency and locations of measurements. Rollover occurrences are the driver for the need for this data. Safety considerations were a factor in the responses from most groups questioned. The LANL safety assessment considers several possibilities. Drop accidents were one such possibility, where knowledge of the yield strength and viscosity at low shear rates would allow better estimates of the effect of instrumentation falling through the nonconvective region. Better estimates of these effects would allow less conservatively imposed operational controls during installation/removal of tank equipment. LANL has expressed no interest in measurements in the convective layer, because it is already understood sufficiently well. Another consideration is the effect of the mixer pump on various instrumentation presently residing or planned to be resident in the tank, such as the sonic probe or the VDTTs (velocity density temperature trees) or the MITs (multi-functional instrument trees). As the mixer pump is operated, fluid flow past these instruments and the mixer pump itself can result in force loads and bending moments and vibrations, which may result in critical damage to the instrumentation. In lieu of firm in-situ data, levels of conservativeness have been employed that make the design and operation of any in-tank equipment difficult to accomplish. The density and the rheological properties (particularly the 
viscosity) of the fluid are necessary ingredients in the estimation of fluid-flow effects past instrumentation. Momentum transfer to the instrumentation will depend on the density, viscosity, and the fluid strain rate, which is related to the fluid velocity. It may be that we will require the viscosity at strain rates greater than what is ultimately obtainable from our modeling and our measurements. However, since viscosity is believed to decrease with increasing strain rate, we will probably be able to determine an upper bound for the viscosity at higher strain rates that is much more reliable than presently used values.

Safety analysis personnel are also very interested in the mixer pump and its effects on the tank waste. Future pump testing, test plan development, and safety analysis coverage of these tanks require more knowledge of the effectiveness of this mitigation technique. Data are needed in regions of the tank where the mixer pump is pointed during its operation, and in regions where little mixing is expected. The safety group would like to know rheological properties such as the yield strength and the zero shear rate viscosity in the affected region immediately before the pump is operated and as soon as practical after its operation is completed. Some means of quantifying the extent of mixing is needed. The disturbed volume may be quite different in rheological terms from the same volume before pump operation. If significant mixing occurs, the waste may behave in a Newtonian fashion and have no yield strength. Then fluid density, solids fraction, and viscosity may be desired. It may not be possible to determine the viscosity to good precision if it is too low, but an upper bound can be established. Presently, safety analysis is interested in determining the extent of mixing, and as such the boundaries dividing mixed and unmixed material before and after pump operation are important. Detailed rheological information is not necessary to map the boundaries, and accuracy requirements for this particular task are, therefore, extremely relaxed. We need only be able to tell the difference between fluid of very low viscosity and no yield strength and fluid with very high viscosity and substantial yield strength.

Accuracy is important to the safety group, but it is more important to know the uncertainties in the derived rheological properties, which include the yield strength and the viscosity at low strain rates. This uncertainty will be included in safety assessment calculations, and more accurate knowledge will result in less constrained operations. Initial estimates of the probable accuracy of this device are around $30 \%$ to $50 \%$ for both the viscosity and the yield strength and this figure seems acceptable for safety analysis. However, there is no strong driver to stipulate any firm number that must be met in order to be useful. Because they now use viscosities and yield strengths that are believed to be much too high and essentially have no accuracy, there is little question that these measurements will dramatically improve the situation. The message from the safety analysis group is the better the accuracy, the less constrained operations become, and virtually any realized accuracy in the measurements will be a welcome improvement.

The WHC structural group needs theological data so that they can understand the effect that may result on instrumentation as the nonconvective layer, or portions of it, flows past such instrumentation during a rollover event. The density of the material also clearly matters. Their concerns are then largely based on safety and equipment well being. Better estimates of the viscosity, even at low shear rates, will allow more confidence in loading calculations. These estimates need not be precise, because they are operating in a region of high Reynolds number (about 25), and factors of, say two, errors will not change the loading estimate significantly. The mixer pump is their present focus of attention, but other instrumentation, such as the sonic probe and the instrument trees, are also considered or will be considered. They would like to determine the loads and torques applied to the 
mixer pump in the event that a large mass of the nonconvective layer flows past it during a release. They have no interest in the convective layer, because it is already well characterized.

Another problem that is of concern to this group is the analysis of potential seismic events and their possible effect on the tank and instrumentation suspended within it. The behavior of the nonconvective layer when subjected to seismic oscillations will depend on the yield strength of the material and the magnitude of the acceleration. If the nonconvective layer yields and then flows, the consequences for in-tank instrumentation are different (worse) than if this layer does not yield. Therefore, estimates of the yield strength are important to this group, as well as the viscosity after yielding.

This group requires rheological data that is representative of the tank on average, and so measurements from somewhere near the middle of the tank would be appropriate. If the time variation of the rheological parameters is significant, then data are required at a frequency consistent with the time scale of changes. Accuracy requirements are not stringent, but as with the safety group, knowledge of uncertainties is important.

Sometime in the future, the waste will be pumped from this tank to somewhere else. Optimization of the mixing and retrieval process also requires knowledge of the rheological properties of the waste. Data needs as presently envisioned are outlined in a WHC report (P. K. Bhatia. September 1993. Retrieval Technologies Characterization Data Needs, WHC-SD-WM-RD-039). Their data needs are quite extensive, and only a small portion of them can be addressed with the ball rheometer. This report points out a need for yield stress, shear stress, and viscosity measurements over an unspecified range of shear rate. The data are required for equipment design and for transport predictions. Data are needed for both the nonconvective layer and the mixed slurry. Stated accuracy requirements are fairly stringent (density to within $5 \%$ and stress measurements to as low as $10 \%$ ), and the ball rheometer may have difficulty in making sufficiently precise measurements. Their accuracy requirements are not entirely clear at present (for instance, no accuracy requirement for viscosity was mentioned), and annual updates of this report are planned, which will allow better definition of their requirements in the future.

Before the waste is pumped, it will be mobilized and mixed. Knowledge of the yield strength, viscosity, and density distribution is important for both mixing and pumping to an external vessel, as the loads on the pumps and, therefore, the pump sizes and also the effectiveness of a mixing pump will depend on such information. No mention is made in the above report concerning a range of strain rate over which rheological data are needed. After mixing, it is doubtful that we will be able to speak of a convective and a nonconvective layer. The waste should be somewhat homogenous. It will probably not possess a significant yield strength, but will have some viscosity. The ball rheometer method may not be applicable unless the viscosity is quite high, and it is not believed that this will be the case. Estimates for a fully mixed waste (based on experiments with a chemical simulant) indicate a viscosity of around $500 \mathrm{cP}$ for low strain rates, well below the useful range for the ball viscometer if the fluid is Newtonian. The fluid density, or more importantly the density of solids suspended in the fluid, may be of primary interest to this group along with the solids-settling rate, and these data can be obtained with reasonable precision with the ball rheometer. In addition, the ball rheometer would be useful in determining the extent of mixing, simply by probing to observe if any very high viscosity material is still present during a test. Data would be required from somewhere near the middle of the tank. The required accuracy and the range of some parameters has not yet been fully determined. It may be that future versions of the Characterization Data Needs 
Report will provide more definitive information. This group should be revisited as the time for retrieval draws nearer.

\section{Expected Instrument Performance}

It is important for all to realize what the ball rheometer is capable of and understand its limits. Primarily the ball rheometer will be useful in wastes where the viscosity is very high, say greater than $10,000 \mathrm{cP}$. This is because we have a good theoretical understanding of flow around a sphere only at very low Reynolds numbers (less than 0.1 ) where the flow can be described as creeping flow, and this implies low ball velocities. The drag force on the ball scales as the viscosity in a Newtonian fluid and as a complicated function of yield stress and viscosity in a yield-pseudoplastic fluid. High viscosity or a significant yield strength are needed in order to obtain a measurable drag force. As such, the ball rheometer is ideally suited for probing the nonconvective layer. In this region, modeling of the fluid character and the subsequent development of relationships among measured velocities and drag forces and the derived rheological parameters are the major challenges. The-ball rheometer is a poor choice for performing accurate measurements in the convective layer. It may work in a mixed layer where the fluid is nearly Newtonian (with low viscosity) but contains suspended particles. In attempting to probe such a mixed region, very little drag force will be experienced by the ball, either dropping or falling, and accurate estimates of the viscosity will be difficult. Density of such a mixed fluid can be obtained from static measurements with reasonable accuracy (initial estimates indicate less than $2 \%$ error). It is likely that suspended solids fraction can be determined from such measurements. While the ball rheometer may possibly have difficulty giving precise information about the rheology of the mixed region, it can determine the depths to which effective mixing has occurred. The drag on the ball (if being raised) or the effective weight of the ball (if being lowered) will change dramatically at the boundary between the two regions.

For in-situ measurement of rheological properties, the ball rheometer is the method of choice. In a report that will soon be released (K. O. Pasamehmetoglu, C. Unal, and J. N. Edwards. 1994. Comments on Rheology Measurements for the Waste Contained in Hanford Tank 101-SY. Los Alamos National Laboratory), difficulties with measurements performed using standard rheological techniques are discussed. Rheological data obtained with cone and plate viscometers provide data with a large uncertainty and a lack of repeatability, possibly due to the large crystals contained within the waste. The crystal sizes in many cases exceed the cone and plate clearance distance, resulting in grinding of the crystals as the device is operated. Measurements using cylindrical spindles show better results in laboratory tests with a chemical simulant; however, implementing such a device in the tank would represent major difficulties. In addition, even in laboratory testing there is an unresolved issue concerning particle migration during tests with a rotating spindle. This report supports both in-situ and laboratory testing using ball viscometry. This method shows the most promise for reliable accurate rheological measurements both on actual tank samples and for in-situ applications.

Summarizing, the ball rheometer is best suited for quantitative measurements in the nonconvective layer. In the convective layer, it is limited in its quantitative capability for viscosity measurement, and its best use may be to allow a determination of the boundary between the convective and nonconvective layer. In addition, reasonably accurate density measurements will be possible with this device in the convective or mixed region. It should be noted that there is presently little interest in 
obtaining quantitative data about the convective layer, and so the ball rheometer, however limited, may be perfectly acceptable. The same may not be true about regions where strong mixing has occurred. Viscosity information may or may not be obtainable from such a region, depending on the fluid rheology. Detailed accurate information about this region, such as solids content and distribution, solids settling rate, and viscosity may require an altogether different probe operating under different scientific principles.

\section{Summary}

In reviewing the comments received from the representatives of the groups requiring rheological data, some conclusions can be reached. No group has any need for data involving the convective layer, only the nonconvective layer. Data requirements for a mixed region have not been completely formulated to date and this process is ongoing. It is likely that detailed information about a mixed region will become valuable as attention is turned towards the questions concerning the effectiveness of the mixer pumps and other mitigation devices, such as the sonic probe. It is believed that the ball rheometer can provide very useful and fairly accurate rheological data (yield strength and low strain rate viscosity) for the nonconvective layer but will have limited capability for measurement of viscosity in a convective region and maybe a mixed region. The ball rheometer can measure density with good accuracy in a mixed region, but it is not clear if this implies that it can provide sufficiently accurate information about suspended solids distribution or settling times. Concerning investigation of mixing pump effectiveness, it is clear that data should be obtained in the regions affected by the mixing pump, and that such data should be acquired sometime before its operation and sometime after its operation.

Data should also be acquired at other locations within the tank and at intervals consistent with the time scale for changes within the waste. Access locations are limited and it appears that, aside from mixer pump considerations given above, locations near the center of the tank are most useful to all. Practical considerations will limit the spatial extent of viscometer data collection. We may have more flexibility as to the times during which we gather data, so that in addition to regular scheduled (e.g., weekly) sampling, we may be able to sample at special times, like right before or after an expected rollover or operation of the mixer pump.

The advent of the mixer pump has changed our understanding of the cyclic events that used to occur in the tank. It may be that another rollover event such as we have become accustomed to observing never occurs again so long as the pump, or perhaps the sonic probe, is resident in the tank. It is clearly important that we use our measurement methods to analyze the effect of the pump on the nonconvective layer.

There appears to be no requirement for extremely precise rheological data, except for perhaps retrieval purposes. If we can measure yield strength and low strain rate (less than about 10/s) viscosity to within $20 \%$ to $40 \%$, it appears that most parties will be satisfied. It is important to understand and clearly state the uncertainties in our measurements and derived quantities. These uncertainties can then be used to bound calculations. 
Of all methods for performing in-situ measurements of rheological properties, the ball rheometer appears to be the best suited for our applications. Installation difficulties within the tank are minimal, and the associated hardware are relatively simple. Only the ball and cable are deployed within the tank (no additional sensors or electrical devices or hydraulic systems), thereby minimizing safety concerns. In addition to its simplicity, the ball rheometer is believed to be the best choice for obtaining reliable accurate rheological data for the nonconvective layer. 


\section{Distribution}

No. of

Copies

\section{OFFSITE}

12 DOE Office of Scientific and Technical Information

Billy C. Hudson 202 Northridge $\mathrm{Ct}$.

Lindsborg, KS 67456

J. L. Kovach

Nuclear Consulting Services, Inc.

P.O. Box 29151

Columbus, OH 43229-0151

Thomas E. Larson

Los Alamos National Laboratory

MS-P915, DX-DO

P.O. Box 1663

Los Alamos, NM 87545

2 Los Alamos National Laboratory

P.O. Box 1663

Los Alamos, NM 87545

Attn: J. R. White, K555

K. Pasamehmetoglu, K555

D. Pepson

U.S. Department of Energy

Trevion II Building, EM-35

Washington, D.C. 20585-0002

Dana Powers

Sandia National Laboratory

Dept. 6404/MS-0744

P.O. Box 5800

Albuquerque, NM 87815-0744
No. of

Copies

ONSITE

4 DOE Richland Operations Office

R. F. Christensen

S7-54

R. E. Gerton

S7-54

J. M. Gray

S7-54

G. W. Rosenwald

S7-54

23 Westinghouse Hanford Company

W. T. Alumkal

S7-85

H. Babad

S7-30

R. E. Bauer

L6-37

G. T. Bear

R1-51

T. R. Benegas

N1-27

L. E. Efferding

H0-33

R. L. Fritz

B4-08

C. E. Hanson

H5-09

G. D. Johnson

N. W. Kirch

L. S. Krogsrud

D. C. Larsen

J. W. Lentsch (5)

R. M. Marusich

S7-15

R2-11

R3-08

R1-51

S7-15

H4-65

N. G. McDuffie

S7-15

M. A. Payne

S7-14

D. A. Reynolds

R2-11

C. P. Shaw

L5-07

J. E. Van Beek 
No of

Copies

31 Pacific Northwest Laboratory

J. M. Alzheimer

W. J. Apley

Z. I. Antoniak

R. M. Bean

S. Q. Bennett

J. B. Colson

E. J Eschbach

J. D. Hudson

B. M. Johnson

F. E. Panisko (5)

K. P. Recknagle

H. C. Reid

P. A. Scott

C. L. Shepard

C. W. Stewart (5)

T. I. Stokes

D. S. Trent

Publishing Coordination

Technical Report Files (5)
K5-22

S7-71

K7-15

P8-08

K7-90

K5-10

K7-15

K7-15

K1-78

P8-34

K7-15

K7-15

P7-43

K5-25

K7-15

H5-09

K7-15 